\title{
Psoriatic spondylitis in a patient with classical rheumatoid arthritis
}

\author{
O. A. THURTLE \\ M.B., M.R.C.P. \\ J. R. PRESTON \\ M.R.C.S., L.R.C.P., D.Phys. Med.

\begin{abstract}
Summary
A patient exhibiting typical features of classical rheumatoid arthritis and psoriatic spondylitis is described. The patient, a woman, presented at the age of 29 with an inflammatory arthritis. Twenty years later, she developed psoriasis, and after a further 3 years, she was first noted to have rheumatoid nodules and to be strongly seropositive. Now at the age of 60 , she has a rigid spine with radiographic changes of spondylitis. Neither rheumatoid arthritis, nor psoriatic spondylitis can account for all the features of her disease and there is evidence to suggest that both conditions combined to damage her peripheral joints.
\end{abstract}

\author{
I. B. DUMBELTON \\ M.B., B.S.
}

P. L. COOK

M.B., F.R.C.R.

\author{
M. I. D. CAWLEY \\ M.D., F.R.C.P.
}

Departments of Rheumatology and Radiology, Southampton General Hospital, Southampton

KEY WORDS: rheumatoid arthritis, psoriatic arthritis, spondylitis.

\section{Introduction}

The erosive arthropathies of psoriatic and rheumatoid type possess distinctive features and for some time have been regarded as separate entities. One distinction between the conditions is that patients with psoriatic arthropathy are serologically negative for rheumatoid factor. Thus, when a patient with an erosive arthropathy is serologically positive for IgM rheumatoid factor, but also has psoriasis, this is assumed to be a chance association. A further difference is that spondylitis is not a feature of rheumatoid arthritis but may occur in patients with psoriatic arthritis and constitutes one form of the latter disease (Roberts et al., 1976). We describe a case in whom the clinical features are such as to require the diagnosis of rheumatoid arthritis and psoriatic spondylitis.

\section{Case report}

A woman, aged 29, presented in 1951 with swollen ankles. She attended regularly for the next 6 years during which time she developed fusiform deformi- $\frac{0}{\omega}$ ties of her fingers, and her right knee deteriorated to $N$ such an extent that an arthrodesis was performed. 응 She did not return to hospital until she was 49 years of age when she was seen with widespread psoriasis $\vec{z}$ which had developed one year previously.

The latex test for rheumatoid factor was first $\vec{\theta}$ recorded at that time and was positive, but the Rose Waaler titre was only weakly positive at 1 in 8 . Foo months later, the latex test was found to be negative. When repeated 3 years later, it was again positive and a Rose Waaler titre performed then was 1 in 512 . Subcutaneous nodules over the extensor surfaces of $\stackrel{0}{\circ}$

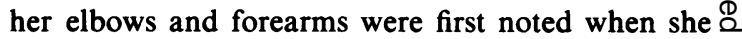
was 52 years of age. One of these nodules was excised $\overrightarrow{\vec{O}}$ and histological examination showed appearances 3 typical of a rheumatoid nodule.

Further studies performed in March 1981 showed her to be clearly sero-positive both by the latex 흘 fixation test and the sheep cell agglutination test with a titre of 1 in 512. She was found to be not HLA B27 욱 positive, but to have a histocompatibility antigen phenotype of A1, A2, B15, B40 and DR4. The distal interphalangeal, as well as the proximal interphalan-

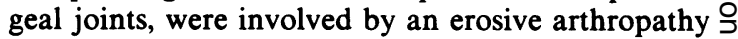
with telescoping of several fingers. There was pitting $\frac{D}{O}$ of the nails.

As well as severe disease of the wrists, elbows and $N$ hips, which could all be found in severe psoriatic or rheumatoid arthritis, she was found to have a completely rigid lumbar and cervical spine, the neck $\omega$ being fixed in flexion. Radiographic examination ${ }^{\circ}$ showed an erosive arthropathy involving the carpus, metacarpophalangeal and both the distal and proxi- $\mathbb{\Phi}$ mal interphalangeal joints of all digits. Cupping of $\stackrel{+}{+}$ the proximal ends of some of the phalanges was also $\frac{T}{0}$ present (Fig. 1). The cervical spine radiographs $\underset{\mathbb{D}}{\stackrel{0}{(}}$ showed syndesmophyte formation with very little $\stackrel{\oplus}{\mathscr{Q}}$ 


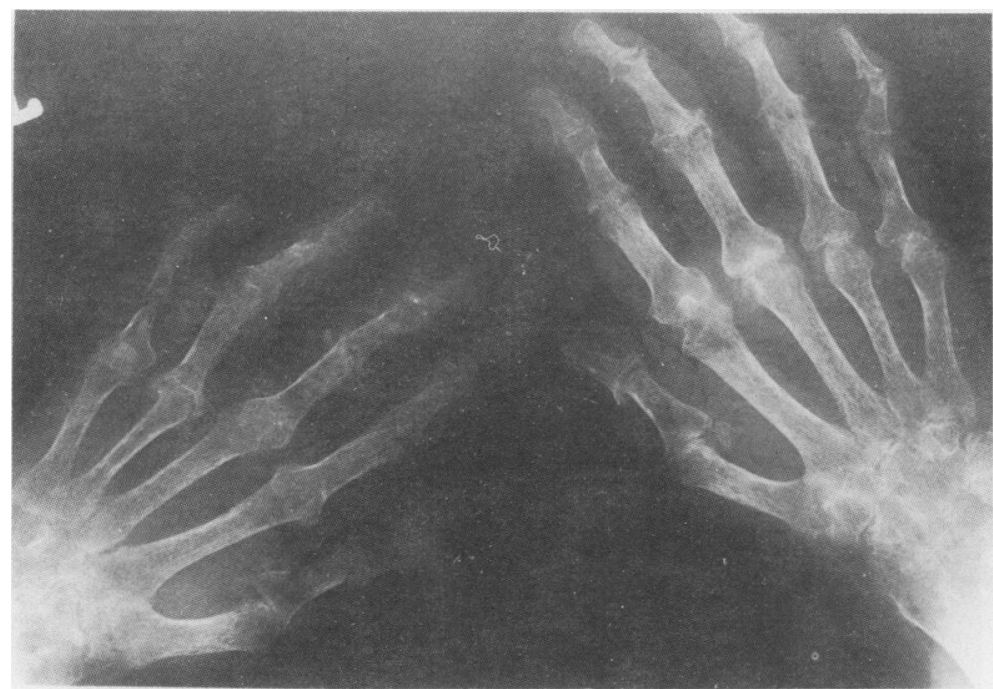

FIG. 1. Radiograph of hands in July 1979 showing advanced erosive arthropathy of distal and proximal interphalangeal, metacarpophalangeal and carpal joints. Cupping of the proximal phalanges is clearly shown in the left hand.

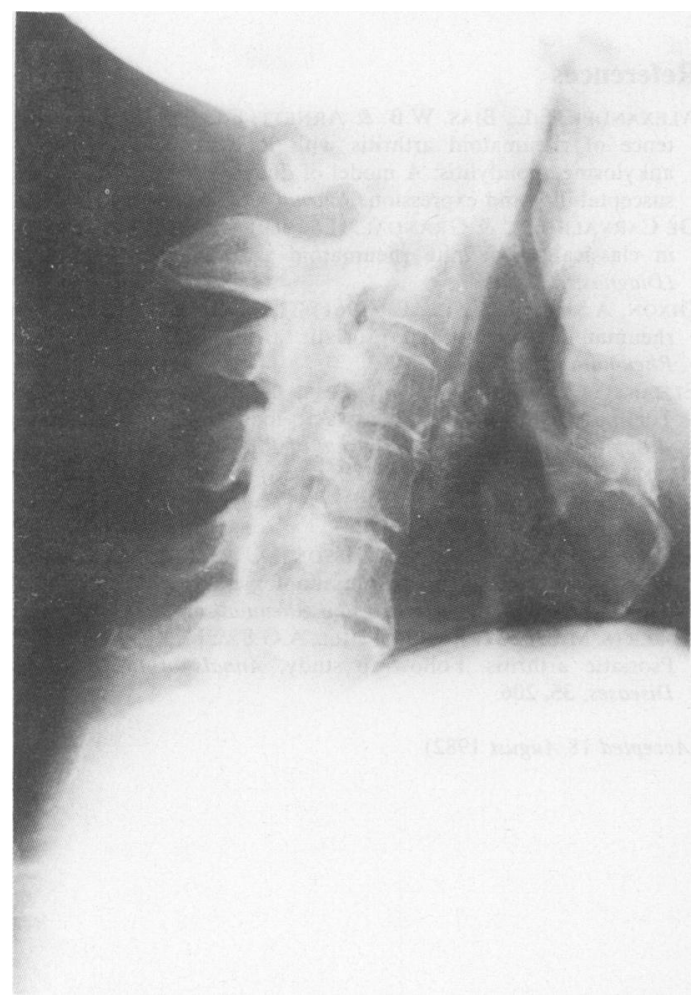

FIG. 2. Lateral radiograph of cervical spine in March 1981 showing a mature syndesmophyte between $\mathrm{C} 5$ and $\mathrm{C} 6$ anteriorly, and early syndesmophyte formation at higher levels. The intervertebral disc spaces are preserved and there is loss of definition of the posterior joints. upper cervical disc degeneration (Fig. 2). Similar changes were noted in the lumbar spine together with 'squaring' of 2 vertebral bodies. Both sacro-iliac joints were widened and showed marginal sclerosis with a large erosion of the right sacro-iliac joint (Fig. 3).

\section{Discussion}

Neither psoriatic or rheumatoid arthritis can fully account for all the features of this patient's disease. The presence of rheumatoid nodules with a high titre of rheumatoid factor establish the diagnosis of classical rheumatoid arthritis, but the radiological changes in the cervical spine cannot be attributed to this condition. The diagnosis of spondylitis is established by the rigidity of the spine and by the presence of syndesmophytes in the cervical spine.

The appearances of the sacro-iliac joints are in keeping with this diagnosis. Tomographic and oblique views reveal abnormalities, such as erosions and intra-articular ankylosis in a significant proportion of patients with rheumatoid arthritis (Elhabali et al., 1979; De Carvalho and Grandal, 1980), but in a study using plain radiographs, only small erosions without sclerosis were observed (Dixon and Lience, 1961). The presence of a large erosion with sclerosis and widening of the sacro-iliac joints is therefore not at all typical of rheumatoid arthritis. The absence of the HLA B27 antigen is compatible with the diagnosis of psoriatic spondylitis in which condition only $50 \%$ of patients carry the antigen (Kammer et al., 1979). 


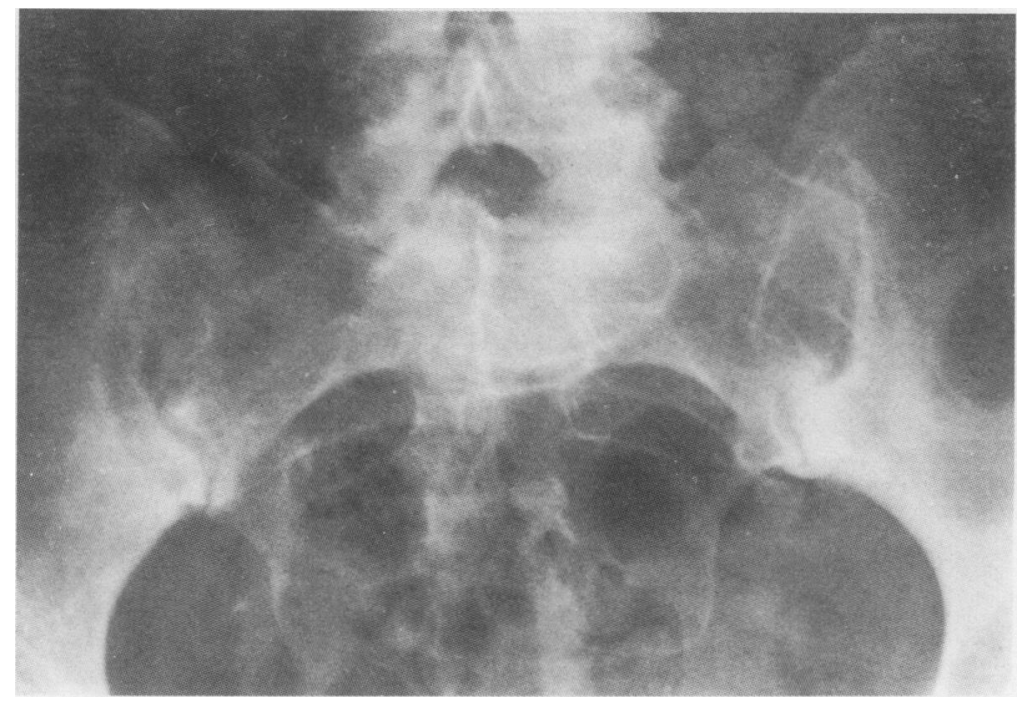

FIG. 3. Radiograph of sacro-iliac joints in June 1974 showing irregular eroded and widened joint spaces with marginal sclerosis inferiorly. The large erosion of the right sacro-iliac joint is obvious.

Others have shown that ankylosing spondylitis and Reiter's disease occasionally coexist with rheumatoid arthritis (Huskisson, 1970; Alexander, Bias and Arnett, 1981), but to our knowledge, psoriatic spondylitis has not previously been reported in a patient with rheumatoid arthritis.

It is usually possible to draw a clear distinction between the sero-positive and sero-negative arthritides and in our patient the psoriasis would have been assumed to be a chance association in a case of rheumatoid arthritis if the spinal changes had not been present. However, the presence of psoriatic spondylitis makes it possible that 2 different disease processes have damaged her limb joints.

The pattern of hand involvement with distal interphalangeal erosions and proximal phalangeal cupping is suggestive of psoriatic rather than rheumatoid arthritis. Perhaps rheumatoid arthritis supervened on established psoriatic arthritis.

\section{References}

Alexander, E.L., Bias, W.B. \& ARnett, F.C. (1981) The coexis $-\infty$ tence of rheumatoid arthritis with Reiter's syndrome andFor ankylosing spondylitis: A model of dual HLA associated disersise susceptability and expression. Journal of Rheumatology, 8, 398

DE CaRvalHo, A. \& GRANDAL, H. (1980) Sacro-iliac involvemętt in classical or definite rheumatoid arthritis. Acta RadiologicaO (Diagnosis), 21, 417.

DixON, A.St.J. \& LIENCE, E. (1961) The sacro-iliac joint in adult骨 rheumatoid arthritis and psoriatic arthropathy. Annals of the Rheumatic Diseases, 20, 247.

Elhabali, M., Scherak, O., Seidl, G. \& Kolarz, G. (1979) Tomographic examinations of sacro-iliac joints in adult patients with rheumatoid arthritis. Journal of Rheumatology, 6, 417.

HUSKISSON, E.C. (for DUDLEY HART, F.) (1970) Ankylosing spon-: dylitis and rheumatoid arthritis. Proceedings of the Royal Societ $\overline{\mathrm{O}}$ of Medicine, 63, 620.

KAMMER, G.M., SOTER, N.A., GiBSON, D.J. \& SCHUR, P.H. (1979)ס் Psoriatic arthritis: a clinical, immunologic and HLA study of $100 \mathrm{~B}$ patients. Seminars in Arthritis and Rheumatism, 9, 75.

ROBERTS, M.E.T., WRIGHT, V., HILL, A.G.S. \& MEHRA, A.C. (1976) Psoriatic arthritis. Follow-up study. Annals of the Rheumatic Diseases, 35, 206.

(Accepted 18 August 1982) 